\title{
Article \\ Evaluation of the Clinical Utility of Genomic Profiling to Inform Selection of Clinical Trial Therapy in Salivary Gland Cancer
}

\author{
Samuel Rack ${ }^{1}$, Laura Feeney ${ }^{2}$, Brindley Hapuarachi ${ }^{3}$, Helen Adderley ${ }^{1}$, Laura Woodhouse ${ }^{1}$, Guy Betts ${ }^{4}$, \\ George J. Burghel ${ }^{5}$, Kevin J. Harrington ${ }^{6}$ and Robert Metcalf ${ }^{1, *}$
}

\section{check for}

updates

Citation: Rack, S.; Feeney, L.;

Hapuarachi, B.; Adderley, H.;

Woodhouse, L.; Betts, G.; Burghel,

G.J.; Harrington, K.J.; Metcalf, R.

Evaluation of the Clinical Utility of

Genomic Profiling to Inform

Selection of Clinical Trial Therapy in Salivary Gland Cancer. Cancers 2022, 14, 1133. https://doi.org/10.3390/ cancers14051133

Academic Editor: Jonas Cicenas

Received: 12 January 2022

Accepted: 21 February 2022

Published: 23 February 2022

Publisher's Note: MDPI stays neutral with regard to jurisdictional claims in published maps and institutional affiliations.

Copyright: (C) 2022 by the authors. Licensee MDPI, Basel, Switzerland. This article is an open access article distributed under the terms and conditions of the Creative Commons Attribution (CC BY) license (https:// creativecommons.org/licenses/by/ $4.0 /)$
1 Department of Medical Oncology, The Christie Hospital NHS Foundation Trust, Manchester M20 4BX, UK; sam.rack@nhs.net (S.R.); h.adderley@nhs.net (H.A.); laura.woodhouse3@nhs.net (L.W.)

2 The Northern Ireland Cancer Centre, Belfast City Hospital, Lisburn Road, Belfast BT9 7AB, UK; laura.feeney@nhs.net

3 Sheffield Teaching Hospitals NHS Foundation Trust, Glossop Road, Broomhall, Sheffield S10 2JF, UK; sonal.hapuarachi@nhs.net

4 Department of Adult Histopathology, Manchester University NHS Foundation Trust, Oxford Road, Manchester M13 9WL, UK; guy.betts@mft.nhs.uk

5 North West Genomic Laboratory Hub, Manchester Centre for Genomic Medicine, Manchester University NHS Foundation Trust, Oxford Road Rd, Manchester M13 9WL, UK; george.burghel@mft.nhs.uk

6 The Royal Marsden NHS Foundation Trust, Fulham Rd., London SW3 6JJ, UK; kevin.harrington@icr.ac.uk

* Correspondence: robert.metcalf1@nhs.net

Simple Summary: Salivary gland cancer is rare and there is a need to develop new and effective drug therapies. New drugs are in development in the recurrent and metastatic setting that target specific changes within a cancer, some of which can be detected through sequencing of the cancer DNA. This study addressed how useful the DNA sequencing of cancer samples is to inform the decision of which drug therapy within a trial is the best match for each individual patient. We found that using focused DNA panels, including small numbers of genes, helped to match just over one in four patients with salivary gland cancer to drug therapies. The matching rate of the focused panel varied by subtype and was least useful in adenoid cystic carcinoma (ACC), at 7\%. However, in ACC, larger gene panels had added value, identifying matched trial therapies in $40 \%$ of cases.

Abstract: For most patients with salivary gland cancer, there are no effective standard systemic therapies. Although clinical trials of biomarker-led drug therapies have delivered significant recent advances, there remains a need to understand the clinical utility of genomic profiling of cancer as a means to match patients with recurrent or metastatic salivary gland cancer to clinical trial therapies. In total, 209 patients with salivary gland cancers were profiled with 24 gene $(n=209))$ and $>325$ gene $(n=32)$ DNA-based next-generation sequencing panels. A retrospective systematic evaluation was performed to identify the frequency of available matched drug therapies within clinical trials based on the results. The matches were then stratified based upon the level of evidence supporting the drug-biomarker combination being investigated using the ESMO Scale for Clinical Actionability of Molecular Targets (ESCAT) to determine the strength of the clinical rationale for each gene-drug match identified. DNA-based next generation sequencing (NGS) analysis was successful in 175/209 $(84 \%)$ patients with salivary gland cancer. Using the 24-gene NGS panel, actionable alterations were identified in $27 \%(48 / 175)$ patients. Alterations were most frequent in salivary duct carcinoma ( $88 \%)$ characterized by TP53 and/or PIK3CA mutations, with matched trials available for 63\% (10/16). In ACC, biomarker-matched trials were available for $7 \%(8 / 115)$, and no genomic alterations were found in $96 / 115$ (83\%) of ACC patients. TP53 was the most frequently altered gene across all subtypes; however, there were no trials recruiting based on TP53 status. In 32 ACC patients with no genomic alterations using the 24-gene panel, a broader (>325 gene) panel identified alterations in 87\% (27/32) of cases with biomarker-matched trials available in $40 \%(13 / 32)$ cases. This study identified that genomic profiling using focused (24-gene) NGS panels has potential utility in matching to trial therapies for most patients with non-ACC salivary gland cancer. For patients with ACC, broader 
genomic profiling has demonstrated added clinical utility. We describe the application of an approach to classification of levels of evidence which may be helpful to inform the clinician and patient decision making around the selection of clinical trial therapies.

Keywords: salivary gland cancer; adenoid cystic carcinoma; salivary duct carcinoma; molecular profiling; biomarker; clinical trials

\section{Introduction}

Salivary gland cancer (SGC) is a rare disease comprising over 24 histopathological subtypes [1]. Although many patients are cured following surgical resection with or without adjuvant radiation, consensus guidance on the optimum management of recurrent or metastatic disease is based on limited evidence and hindered by the relative paucity of clinical trials incorporating these patients [2].

Although some patients may derive meaningful benefit from cytotoxic chemotherapy [3], there remains limited trial evidence to support its routine use. The most significant recent advances have come from clinical trials of biomarker-directed drug therapies [4-12]. For example, the amplification of Erb-B2 receptor tyrosine kinase 2 (ERBB2/HER2) protein overexpression is seen in $20-30 \%$ of cases of salivary duct carcinoma [13] and there is trial data to support the efficacy of HER2-targeting therapy with either trastuzumab and docetaxel [11], trastuzumab and pertuzumab [12] or trastuzumab-emtansine [10] in recurrent or metastatic ERBB2-amplified/HER2-overexpressing disease. In addition to HER2, the androgen receptor (AR) is overexpressed in most patients with salivary duct carcinoma (SDC) [13]. There are clinical trial data showing the efficacy of either androgen deprivation therapy with bicalutamide [13] and enzalutamide [9] and combined androgen blockade with bicalutamide and triptorelin [8] in recurrent or metastatic AR-overexpressing salivary duct carcinoma.

The other subtype of salivary gland cancer which has been most impacted by the development of biomarker-led therapy is secretory carcinoma. Chromosomal rearrangements resulting in fusions of the Neurotrophic Tyrosine Receptor Kinase (NTRK) gene are described in around $90 \%$ of cases of secretory carcinoma [14] and there are data showing the efficacy of entrectinib [4] and larotrectinib [5] in NTRK-rearranged tumours from any primary site, including NTRK-rearranged salivary gland cancers. Previous studies in SGC identified TP53 and the PI3K pathway as the most commonly altered through point mutations across SGC subtypes. Mutations in ERBB2, EGFR, and BRAF have previously been detected at low frequencies and have the potential to match patients to targeted therapies [15].

Aside from these few examples of biomarker-directed therapies relevant to salivary gland cancers, in order for clinicians to engage in informed discussion with their patients on the potential role for genomic profiling, there is a need to better understand the clinical utility of these approaches. In addition, clinicians increasingly encounter situations in which patients attend consultations seeking an interpretation of genetic sequencing data on their own tumours that they have obtained from commercial vendors. We, therefore, sought to evaluate the frequency with which DNA-based next-generation sequencing (NGS) yields additional information to aid selection of clinical trial drug therapies for a cohort of patients with salivary gland cancer and to judge the strength of the underlying rationale for individual biomarker-drug matches in this population.

\section{Materials and Methods}

\subsection{Patient Consent and Clinical Data Collection}

We performed a retrospective cohort study on 209 patients with salivary gland cancers who underwent clinical review at a tertiary cancer centre (The Christie NHS Foundation Trust, Manchester, UK) from April 2017 to December 2020. Patients provided informed con- 
sent for the collection of genomic, clinical and demographic characteristics. This study was granted research ethics approval under the Manchester Cancer Research Centre Biobank Research Tissue Bank Ethics (NHS NW Research Ethics Committee 18/NW/0092) and was performed in accordance with the Declaration of Helsinki.

\subsection{Next-Generation Sequencing}

For all patients, a focused DNA-based NGS panel was performed including 24 cancerrelated genes through the course of this study. The genes included and regions of each gene covered are shown in Supplementary Table S1. DNA was extracted from archival FFPE samples, and samples were requested to have a minimum tumour content of $20 \%$ and analysed using a Qiagen GeneRead DNAseq Targeted Panel V2 in the National Health Service Northwest Genomics Laboratory Hub. A median exon coverage depth of $>350 \times$ was performed and a customised bioinformatic pipeline was validated to detect single nucleotide variants and indels $(<40 \mathrm{bp})$ to $4 \%$ mutant allele frequency. Where identified, variants were classified using Cancer Variant Interpretation Guidelines UK [16] and tiering from the joint Consensus Recommendation of the Association for Molecular Pathology, American Society of Clinical Oncology, and College of American Pathologists [17] with reference to publicly available resources including Catalogue Of Somatic Mutations In Cancer v19, and other subscription-based resources including Human Gene Mutation Database Professional (Qiagen). In a secondary analysis, on samples from 32 patients with adenoid cystic carcinoma, in whom no alterations were identified using the focused panel, repeat analysis was performed using a broader DNA-based NGS panel. For these samples, the commercial Foundation Medicine assay was performed in a Clinical Laboratory Improvement Amendments (CLIA)-certified laboratory and accredited by the College of American Pathologists. Tumour DNA underwent hybrid capture for the entire coding region and select introns from genes frequently mutated or rearranged in cancer (including $>325$ selected cancer-related genes through the course of this study). Illumina HiSeq NGS was performed with a median exon coverage depth of $>500 \times$ to identify single-nucleotide variants, indels, copy number alterations and select gene rearrangements (as described in [18]). Summary findings of NGS data were visualised on cBioPortal $[19,20]$.

\subsection{Systematic Evaluation of Genomic Biomarker and Drug Trial Matches}

To link genetic variants to drug therapies within clinical trials, the 24 genes included in the focused panel were queried in the public ally available databases OncoKB [21] and MyCancerGenome.org to identify pre-existing biomarker-therapy matches and biomarkerled studies, respectively. To identify preclinical evidence for biomarkers associated with response to targeted therapies, literature searches of PubMed were undertaken using the search terms "GENE NAME" and ("predictive biomarker" OR "Targeted therapy" OR "Response" OR "sensiti*"). To determine whether any clinical trials were available in the UK incorporating these therapies and open to patients with salivary gland cancers, a search was performed on the clinicaltrials.gov database for trials open to recruitment to patients with salivary gland cancers or any solid tumour type using therapies established from the above process with sites active in the UK from 2016 to December 2020.

\subsection{Classification of Level of Evidence}

Genomic findings were ranked using the European Society of Clinical Oncology (ESMO) Scale for Clinical Actionability of Molecular Targets (ESCAT) scoring system [22] independently by two co-authors (S.R. and L.W.). When different scores were allocated, a further review was undertaken by R.M. and a final consensus reached. The ESCAT scaling defines six tiers of clinical evidence supporting the actionability of genomic-drug matches as follows: Level I, genomic-drug matches ready for implementation in routine clinical decisions; level II, genomic-drug matches as investigational targets that are likely to define a patient population that benefits from a targeted drug but additional data are needed; level III, genomic-drug matches with clinical benefit previously demonstrated in other tumour 
types or for similar molecular targets; level IV, genomic-drug matches with preclinical evidence of actionability; level $\mathrm{V}$, genomic-drug matches with evidence supporting cotargeting approaches; and level X, genomic findings with lack of evidence for actionability. For the ESCAT classification of each gene under investigation, the highest score was taken when different specific variants within the same gene carried different scores.

\section{Results}

\subsection{Patient Characteristics}

A total of 209 patients with salivary gland cancer reviewed at a single tertiary cancer centre between 2017 and 2019 were included in this study. The clinical characteristics of the patients are shown in Table 1. Consistent with a population of patients seeking clinical trial therapies, the median age was 51 years (range: 23-78 years) and almost all patients $(91 \%)$ had radiological confirmation of recurrent or metastatic disease with a measurable component at the time of review. In total, $44 \%$ of patients had tumours arising in the minor salivary gland consistent with the relatively high frequency of disease recurrence in this population [23]. ACC was the most frequent histopathology (68\%), as would be expected given the relatively high risk of recurrence in this subtype. Of the remaining patients with non-ACC SGC, adenocarcinoma not otherwise specified (NOS) and SDC were most frequent.

Table 1. Clinical characteristics of patients with salivary gland cancer undergoing genomic profiling. Abbreviations: NGS. Next-generation sequencing; ACC (Adenoid Cystic Carcinoma); Acinic (Acinic Cell Carcinoma); Adeno (Adenocarcinoma); ExPleo (Carcinoma ex Pleomorphic Adenoma); SDC (Salivary duct carcinoma); MyoE (Myo-epithelial Carcinoma); MEC (Mucoepidermoid carcinoma); NEC (Neuro-endocrine carcinoma); Secretory (Secretory carcinoma); NUT (NUT carcinoma).

\begin{tabular}{|c|c|c|c|c|c|c|c|}
\hline \multirow[t]{2}{*}{ Characteristic } & \multirow[t]{2}{*}{ Subgroup } & \multicolumn{2}{|c|}{ Total } & \multicolumn{2}{|c|}{ NGS Successful } & \multicolumn{2}{|c|}{ NGS Failed } \\
\hline & & Number & Percentage & Number & Percentage & Number & Percentage \\
\hline All Patients & & 209 & 100 & 175 & 84 & 34 & 16 \\
\hline \multirow{2}{*}{ Sex } & Female & 113 & 54 & 93 & 53 & 20 & 59 \\
\hline & Male & 96 & 46 & 82 & 47 & 14 & 41 \\
\hline \multirow{2}{*}{ Age } & Median & 51 & & 51 & & 51 & \\
\hline & Range & $13-78$ & & $13-77$ & & $23-78$ & \\
\hline \multirow{2}{*}{ Site } & Minor & 93 & 44 & 75 & 43 & 18 & 53 \\
\hline & Major & 116 & 56 & 100 & 57 & 16 & 47 \\
\hline \multirow[b]{2}{*}{$\mathrm{R} / \mathrm{M}$ disease } & Yes & 190 & 91 & 159 & 91 & 31 & 91 \\
\hline & No & 19 & 9 & 16 & 9 & 3 & 9 \\
\hline \multirow{5}{*}{$\begin{array}{l}\text { Metastatic } \\
\text { sites }\end{array}$} & Local & 78 & 37 & 56 & 32 & 22 & 65 \\
\hline & Lung & 121 & 58 & 99 & 57 & 22 & 65 \\
\hline & Bone & 37 & 18 & 32 & 18 & 5 & 15 \\
\hline & Liver & 22 & 11 & 22 & 13 & 0 & 0 \\
\hline & Other & 24 & 11 & 21 & 12 & 3 & 9 \\
\hline \multirow{10}{*}{ Subtypes } & $\mathrm{ACC}$ & 142 & 68 & 115 & 66 & 27 & 79 \\
\hline & Adeno & 18 & 9 & 15 & 9 & 3 & 9 \\
\hline & SDC & 17 & 8 & 16 & 9 & 1 & 3 \\
\hline & Acinic & 9 & 4 & 8 & 5 & 1 & 3 \\
\hline & ExPleo & 8 & 4 & 8 & 5 & 0 & 0 \\
\hline & MEC & 7 & 3 & 6 & 3 & 1 & 3 \\
\hline & MyoE & 5 & 2 & 4 & 2 & 1 & 3 \\
\hline & NEC & 1 & 1 & 1 & 1 & 0 & 0 \\
\hline & Secretory & 1 & 1 & 1 & 1 & 0 & 0 \\
\hline & NUT & 1 & 1 & 1 & 1 & 0 & 0 \\
\hline
\end{tabular}




\subsection{Next-Generation Sequencing with 24-Gene Targeted Panel}

\subsubsection{Systematic Evaluation of Matched Drug Therapies within Clinical Trials}

To facilitate personalised clinical trial selection, a focused DNA-based NGS panel including 24 genes frequently associated with somatic mutations in cancer (Table S1) was applied to FFPE tumour samples from 209 patients with salivary gland cancers being reviewed to consider clinical trial therapies. To determine the utility of this panel to guide clinical trial selection, we performed a systematic evaluation of genomic biomarker-drug trial matches. Table 2 summarises the genes included in this panel and the matched drug therapies available through the course of this study.

Table 2. Components of focused NGS panel and matched drug therapies. Biomarkers were classified based on ESCAT. The ESCAT score is attributed to specific gene variants as outlined in the original papers referenced. Only evidence for point mutations and small insertions and deletions are included. Other genetic alterations such as copy number variations are not included as they were not analysed in our panel.

\begin{tabular}{|c|c|c|c|}
\hline GENE & ESCAT & Open Biomarker Selected Trials & Drug (Targeted Pathway) \\
\hline AKT1 & 3a [24] & $\begin{array}{c}\text { NCT03673787 } \\
\text { NCT01226316, NCT02338622 }\end{array}$ & $\begin{array}{l}\text { Ipatasertib (AKT1 inhibitor) } \\
\text { AZD5363 (AKT1 inhibitor) }\end{array}$ \\
\hline $\mathrm{AR}$ & 4a [25] & No trial & - \\
\hline ALK & 3a [26] & No trial & - \\
\hline BRAF & 3a [27] & NCT02407509 & RO5126766 (Raf/MEK inhibitor) \\
\hline CTNNB1 & 4a $[28]$ & No trial & - \\
\hline DDR2 & 4a [29] & No trial & - \\
\hline EGFR & 3a [30] & NCT04259450 & AFM24 (anti-EGFR antibody) \\
\hline ERBB2 & $3 a / 3 b[6,10]$ & $\begin{array}{l}\text { NCT01953926 } \\
\text { NCT03410927 }\end{array}$ & $\begin{array}{l}\text { Neratinib (Pan-Her inhibitor) } \\
\text { TAS0728 (Her-2 inhibitor) }\end{array}$ \\
\hline FGFR2 & $4 \mathrm{a}[31]$ & $\begin{array}{c}\text { NCT02052778, NCT04189445 } \\
\text { NCT04083976 } \\
\text { NCT03822117 }\end{array}$ & $\begin{array}{l}\text { Futibatinib (FGFR inhibitor) } \\
\text { Erdafitinib (FGFR inhibitor) } \\
\text { Pemigatinib (FGFR inhibitor) }\end{array}$ \\
\hline GNA11 & 4a [32] & No trial & - \\
\hline GNAQ & 4a [32] & No trial & - \\
\hline IDH1 & 3a [33] & NCT03684811 & Olutasidenib (IDH1 inhibitor) \\
\hline IDH2 & 3a [34] & No trial & - \\
\hline KIT & 3a [35] & NCT02571036 & Ripretinib (KIT/PGDRa inhibitor) \\
\hline KRAS & 4a $[27,36]$ & NCT02407509 & RO5126766 (Raf/MEK inhibitor) \\
\hline MAP2K1 & 3a [36] & NCT02407509 & RO5126766 (Raf/MEK inhibitor) \\
\hline MET & 3a [37] & NCT02925104 & Capmatinib (MET inhibitor) \\
\hline NRAS & 3a [36] & NCT02407509 & RO5126766 (Raf/MEK inhibitor) \\
\hline PDGFRa & 3a [35] & NCT02508532 & Avapritinib (PDGFRa inhibitor) \\
\hline PIK3CA & $2 b[38]$ & $\begin{array}{c}\text { NCT01226316, NCT02338622 } \\
\text { NCT03006172 }\end{array}$ & $\begin{array}{l}\text { AZD5363 (AKT1 inhibitor) } \\
\text { GDC-0077 (Pi3K inhibitor) }\end{array}$ \\
\hline PTEN & 3a [39] & $\begin{array}{c}\text { NCT03673787 } \\
\text { NCT01226316, NCT02338622 }\end{array}$ & $\begin{array}{l}\text { Ipatasertib (AKT1 inhibitor) } \\
\text { AZD5363 (AKT1 inhibitor) }\end{array}$ \\
\hline RET & 3a $[40]$ & $\begin{array}{l}\text { NCT03037385 } \\
\text { NCT03157128 }\end{array}$ & $\begin{array}{l}\text { Pralsetinib (RET inhibitor) } \\
\text { Selpercatinib (RET inhibitor) }\end{array}$ \\
\hline STK11 & 4a [41] & No trial & - \\
\hline TP53 & 4a [42] & No trial & - \\
\hline
\end{tabular}


Although all of the genes included in this panel had the potential to match patients to drug therapies, through the duration of this study, matched drug therapies within trials were open to SGC/solid malignancy patients for $63 \%(15 / 24)$ of the sequenced genes. To classify the level of evidence supporting the genomic biomarker under investigation, genomic findings were ranked using the ESCAT scoring system [22]. None of the genomic alterations was classed as level 1, defined as the drug-target match being associated with improved outcome in clinical trials in the specific tumour type. The highest ESCAT score was for PIK3CA at level 2b, as clinical trial results of drugs targeting this pathway have demonstrated a signal of increased radiological response rate without data showing a meaningful overall survival benefit [38].The remainder were classed as level $3(12 / 15)$, defined as demonstrating clinical benefit in other tumour types or in similar variants, or level $4 \mathrm{a}(2 / 15)$, defined as actionability of target predicted in preclinical in vitro or in vivo models.

Applying the 24-gene NGS panel to a consecutive series of 209 patients with salivary gland cancer considering trial therapies, the analysis through NGS was successful in 175 cases $(84 \%)$. The remainder failed due to insufficient or poorly preserved DNA. Figure 1 shows the results of the focused NGS analysis on 175 patients with salivary gland cancer. Sixty-three variants of significance were identified in 48 patients (27\%). The most frequently altered genes were PIK3CA and TP53, which made up 61\% (39/63) of all alterations identified. The frequency of alterations was lowest for patients with ACC (19/115, 17\%) compared with non-ACC SGC (29/60, 50\%). The highest frequency of alterations seen using this approach was for patients with SDC which was characterised by the presence of TP53 and/or PIK3CA mutations in 14/16 cases. Patients with myoepithelial, neuroendocrine $(n=1)$, NUT $(n=1)$ and secretory $(n=1)$ carcinomas had no identifiable mutations with this panel.

\begin{tabular}{|c|c|c|c|c|c|c|c|}
\hline \multicolumn{8}{|c|}{ A Adenoid Cystic Carcinoma $(n=115)$} \\
\hline TP53 & $10 \%$ & \multicolumn{6}{|c|}{ 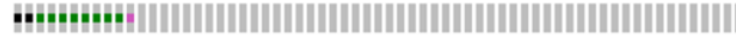 } \\
\hline PTEN & $3 \%$ & \multicolumn{6}{|l|}{ 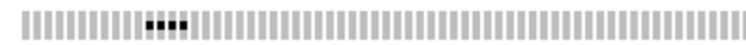 } \\
\hline AKT1 & $0.9 \%$ & \multicolumn{6}{|l|}{. $\|H\|$} \\
\hline PIK3CA & $1.7 \%$ & \multicolumn{6}{|l|}{$\|$} \\
\hline EGFR & \multicolumn{7}{|c|}{$0.9 \%$ ||||| } \\
\hline CTNNB1 & \multicolumn{7}{|l|}{$0.9 \%$} \\
\hline BRAF & \multicolumn{7}{|c|}{$0.9 \%$} \\
\hline \multicolumn{2}{|l|}{ B } & \begin{tabular}{|l|} 
SDC \\
$(n=16)$
\end{tabular} & $\begin{array}{l}\text { Adeno } \\
(n=15)\end{array}$ & $\begin{array}{l}\text { ExPleo } \\
(n=8)\end{array}$ & $\begin{array}{l}\text { Acinic } \\
(n=8)\end{array}$ & \begin{tabular}{|l|} 
MEC \\
$(n=6)$
\end{tabular} & $\begin{array}{l}\text { Other } \\
(n=7)\end{array}$ \\
\hline TP53 3 & & \multicolumn{6}{|c|}{ 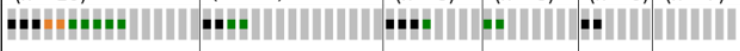 } \\
\hline PIK3CA 1 & & 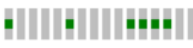 & $\|$ & 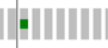 & |||||| & III & \\
\hline ERBB2 5 & & HHHIII & & $H$ & & & \\
\hline AKT1 3 & $3 \%$ & |HHIH|| & & & & & \\
\hline PTEN & $3 \%$ & \|\|\|\| & H & & & & \\
\hline BRAF 1 & $1.7 \%$ & \|\|$\|||||||$ & 川 & H & & III & \\
\hline KRAS 1 & $1.7 \%$ & \|\|\|\| & 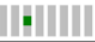 & $\|$ & $|\||$ & 10 & \\
\hline
\end{tabular}

Missense Mutation (putative driver)

Splice Mutation (putative driver)

Truncating Mutation (putative driver)

Other Mutation

No alterations

Figure 1. Results of DNA-based next-generation sequencing from patients with salivary gland cancer ( $n=175$ ) using 24-gene NGS panel. (A) Adenoid Cystic Carcinoma (ACC). (B) Patients with other (non-ACC) histopathological subtypes. Other includes neuroendocrine carcinoma $(n=1)$, secretory carcinoma $(n=1)$ and NUT carcinoma $(n=1)$. Individual patient results are represented by a column of vertical bars. Only genes in which alterations were detected are shown. Detection of genomic alterations are indicated by coloured bars, and the absence of alterations is indicated by grey bars.

\subsection{2. ТP53}

TP53 alterations were the most frequent finding, with 34 mutations identified in 33 samples (Table 3). These were missense mutations in 19/34, and 12/34 were truncation 
mutations. One sample had a silent mutation, TP53 c.375G > A p.(Thr125Thr). However, this variant has been shown to lead to in intron inclusion between exons 4 and 5 and is therefore pathogenic. Depicted as "other" in Figure 1, further mutations occurred at splice sites, resulting in pathogenic changes. Although TP53 alterations were the most frequent finding, the drug-biomarker combinations are under investigation in trials based upon pre-clinical (level 4a evidence), and there were no open trials with a rationale for the inclusion of patients with TP53 mutations through the course of this study. Level 4a was allocated based on preclinical data with ATR inhibitors. TP53-mutant tumours were shown to have increased sensitivity to ATR inhibitors in combination with chemotherapy or radiotherapy [42].

Table 3. Full list of significant alterations as classified by CanVIG [16,17]. Grouped by gene. ACCadenoid cystic carcinoma; Acinic_-acinic cell carcinoma, ADENO_-adenocarcinoma not otherwise specified; ExPleo Carcinoma—expleomorphic adenoma; MEC—-mucoepidermoid carcinoma; SDC— salivary ductal carcinoma.

\begin{tabular}{|c|c|c|c|c|c|}
\hline Patient & Subtype & Variant & Patient & Subtype & Variant \\
\hline ACC1 & ACC & $\begin{array}{c}\text { TP53 c.832C > T p.(Pro278Ser) } \\
17 \% \text { reads }\end{array}$ & ACC16 & ACC & $\begin{array}{c}\text { PIK3CA c. } 1633 \mathrm{G}>\mathrm{A} \\
\text { p.(Glu545Lys) } 11 \% \text { reads }\end{array}$ \\
\hline ACC3 & ACC & $\begin{array}{c}\text { TP53 c.814G > T p. }(\text { Val272Leu }) \\
4 \% \text { reads }\end{array}$ & ACC19 & ACC & $\begin{array}{c}\text { PIK3CA c.1258T > C } \\
\text { p.(Cys420Arg) 18\% reads; }\end{array}$ \\
\hline ACC10 & ACC & $\begin{array}{c}\text { TP53 c.328delC } \\
\text { p.(Arg110ValfsTer13) } \% \% \text { reads }\end{array}$ & ACC19 & ACC & $\begin{array}{c}\text { PIK3CA c. } 1633 \mathrm{G}>\mathrm{A} \\
\text { p.(Glu545Lys) } 8 \% \text { reads }\end{array}$ \\
\hline ACC13 & ACC & $\begin{array}{c}\text { TP53 c.1146delA } \\
\text { p.(Lys382AsnfsTer40) 29\% reads }\end{array}$ & ACINIC25 & ACINIC & $\begin{array}{c}\text { PIK3CA c.3140A > G } \\
\text { p.(His1047Arg) } 23 \% \text { reads }\end{array}$ \\
\hline ACC14 & ACC & $\begin{array}{c}\text { TP53 c.375G > A p.(Thr125Thr) } \\
28 \% \text { reads }\end{array}$ & ADENO32 & ADENO & $\begin{array}{c}\text { PIK3CA c. } 1636 \mathrm{C}>\mathrm{A} \\
\text { p.(Gln546Lys) } 36.41 \% \text { reads }\end{array}$ \\
\hline ACC15 & ACC & $\begin{array}{c}\text { TP53 c.584T > C p.(Ile195Thr) } \\
\text { 7\% reads }\end{array}$ & ExPleo35 & ExPleo & $\begin{array}{c}\text { PIK3CA c.1633G > A } \\
\text { p.(Glu545Lys) 39\% reads }\end{array}$ \\
\hline ACC18 & ACC & $\begin{array}{c}\text { TP53 c.373A > G p.(Thr125Ala) } \\
\text { 14\% reads }\end{array}$ & SDC44 & SDC & $\begin{array}{c}\text { PIK3CA c. } 1624 \mathrm{G}>\mathrm{A} \\
\text { p.(Glu542Lys) } 13 \% \text { reads }\end{array}$ \\
\hline ACC19 & ACC & $\begin{array}{c}\text { PIK3CA c. } 1633 \mathrm{G}>\mathrm{A} \\
\text { p.(Glu545Lys) } 8 \% \text { reads }\end{array}$ & SDC45 & SDC & $\begin{array}{c}\text { PIK3CA c. } 1093 \mathrm{G}>\mathrm{A} \\
\text { p.(Glu365Lys) } 20 \% \text { reads }\end{array}$ \\
\hline ACC21 & ACC & $\begin{array}{c}\text { TP53 c.329G > C p.(Arg110Pro) } \\
50 \% \text { reads }\end{array}$ & SDC46 & SDC & $\begin{array}{c}\text { PIK3CA c. } 3140 A>\text { G } \\
\text { p.(His1047Arg) 13\% reads }\end{array}$ \\
\hline ACC22 & ACC & $\begin{array}{c}\text { TP53 c.824G > A p.(Cys275Tyr) } \\
4 \% \text { reads }\end{array}$ & SDC47 & SDC & $\begin{array}{c}\text { PIK3CA c. } 1624 \mathrm{G}>\mathrm{A} \\
\text { p.(Glu542Lys) } 13 \% \text { reads }\end{array}$ \\
\hline ACC22 & ACC & $\begin{array}{c}\text { TP53 c.467G > C p.(Arg156Pro) } \\
8 \% \text { read }\end{array}$ & SDC49 & SDC & $\begin{array}{c}\text { PIK3CA c. } 3140 A>\text { G } \\
\text { p.(His1047Arg) } 10 \% \text { reads }\end{array}$ \\
\hline ACC24 & ACC & $\begin{array}{c}\text { TP53 c.1010G > A p.(Arg337His) } \\
13 \% \text { reads }\end{array}$ & SDC52 & SDC & $\begin{array}{c}\text { PIK3CA c.3140A > G } \\
\text { p.(His1047Arg) 51\% reads }\end{array}$ \\
\hline ACINIC25 & ACINIC & $\begin{array}{c}\text { TP53 c.742C > T p. }(\text { Arg248Trp }) \\
4 \% \text { reads }\end{array}$ & ACC1 & ACC & $\begin{array}{c}\text { AKT1 c.49G > A p.(Glu17Lys) } \\
4 \% \text { reads }\end{array}$ \\
\hline ACINIC26 & ACINIC & $\begin{array}{c}\text { TP53 c.818G > T p.(Arg273Leu) } \\
\text { 35\% reads }\end{array}$ & SDC54 & SDC & $\begin{array}{c}\text { AKT1 c.49G > A p.(Glu17Lys) } \\
22 \% \text { reads }\end{array}$ \\
\hline ADENO27 & ADENO & $\begin{array}{c}\text { TP53 c.794T > G p.(Leu265Arg) } \\
\text { 37\% reads }\end{array}$ & SDC56 & SDC & $\begin{array}{c}\text { AKT1 c.49G > A p.(Glu17Lys) } \\
19 \% \text { reads }\end{array}$ \\
\hline ADENO28 & ADENO & $\begin{array}{c}\text { TP53 c.637C > T p. }(\text { Arg213Ter }) \\
26 \% \text { reads }\end{array}$ & ACC5 & ACC & $\begin{array}{c}\text { PTEN c.829dup } \\
\text { p.(Thr277AsnfsTer21) } 9 \% \text { reads }\end{array}$ \\
\hline ADENO29 & ADENO & $\begin{array}{c}\text { TP53 c.626_627delGA } \\
\text { p.(Arg209LysfsTer6) 30\% reads }\end{array}$ & ACC7 & ACC & $\begin{array}{c}\text { PTEN c.750_765dup } \\
\text { p.(Glu256TrpfsTer2) 52\% reads }\end{array}$ \\
\hline ADENO30 & ADENO & $\begin{array}{c}\text { TP53 c.481G > A p.(Ala161Thr) } \\
\text { 22\% reads; }\end{array}$ & ACC12 & ACC & $\begin{array}{c}\text { PTEN c.16A > T p.(Lys6Ter) } \\
62 \% \text { reads }\end{array}$ \\
\hline ExPleo34 & ExPleo & $\begin{array}{c}\text { TP53 c.686_687dupGT } \\
\text { p.(Thr230ValfsTer18) 38\% reads }\end{array}$ & ACC17 & ACC & $\begin{array}{c}\text { PTEN c.686C > G p.(Ser229Ter) } \\
12 \% \text { reads }\end{array}$ \\
\hline ExPleo35 & ExPleo & $\begin{array}{c}\text { TP53 c.991C > T p.(Gln331Ter) } \\
44 \% \text { reads; }\end{array}$ & ADENO31 & ADENO & $\begin{array}{c}\text { PTEN c.382A > C p.(Lys128Gln) } \\
7 \% \text { reads }\end{array}$ \\
\hline ExPleo36 & ExPleo & $\begin{array}{c}\text { TP53 c.750_754dupCATCC } \\
\text { p.(Leu252ArgfsTer95) 20\% reads }\end{array}$ & MEC40 & MEC & PTEN c. $634+5 \mathrm{G}>\mathrm{T} 42 \%$ reads \\
\hline
\end{tabular}


Table 3. Cont.

\begin{tabular}{|c|c|c|c|c|c|}
\hline Patient & Subtype & Variant & Patient & Subtype & Variant \\
\hline ExPleo37 & ExPleo & $\begin{array}{c}\text { TP53 c.989T > G p.(Leu330Arg) } \\
26 \% \text { reads }\end{array}$ & ACC4 & $\mathrm{ACC}$ & $\begin{array}{c}\text { EGFR c.2369C > T p. }(\text { Thr790Met }) \\
31 \% \text { reads }\end{array}$ \\
\hline MEC38 & MEC & $\begin{array}{c}\text { TP53 c.828delC } \\
\text { p.(Cys277ValfsTer68) 7\% reads }\end{array}$ & ExPleo36 & ExPleo & $\begin{array}{c}\text { ERBB2 c.2305G > C p.(Asp769His) } \\
81 \% \text { reads }\end{array}$ \\
\hline MEC39 & MEC & $\begin{array}{c}\text { TP53 c.733G > A p.(Gly245Ser) } \\
\text { 15\% reads }\end{array}$ & SDC43 & SDC & $\begin{array}{c}\text { ERBB2 c.929C > T p.(Ser310Phe }) \\
34 \% \text { reads }\end{array}$ \\
\hline MEC41 & MEC & $\begin{array}{l}\text { TP53 c. } 460 \_462 \text { delGGC } \\
\text { p.(Gly154del) } 60 \% \text { reads }\end{array}$ & SDC50 & SDC & $\begin{array}{c}\text { ERBB2 c.2305G }>\text { C p.(Asp769His) } \\
26 \% \text { reads }\end{array}$ \\
\hline SDC42 & SDC & $\begin{array}{c}\text { TP53 c.839G > C p.(Arg280Thr) } \\
14 \% \text { reads }\end{array}$ & ACC11 & $\mathrm{ACC}$ & $\begin{array}{c}\text { BRAF c.1397G > A p.(Gly466Glu) } \\
27 \% \text { reads }\end{array}$ \\
\hline SDC43 & SDC & TP53 c.993 + 1G > T 41\% reads & SDC45 & SDC & $\begin{array}{c}\text { BRAF c. } 1780 \text { G > A p.(Asp594Asn) } \\
20 \% \text { reads; }\end{array}$ \\
\hline SDC45 & SDC & $\begin{array}{c}\text { TP53 c.374C > G p.(Thr125Arg) } \\
22 \% \text { reads }\end{array}$ & ADENO27 & ADENO & $\begin{array}{c}\text { KRAS c.436G > A p.(Ala146Thr) } \\
8 \% \text { reads }\end{array}$ \\
\hline SDC48 & SDC & $\begin{array}{c}\text { TP53 c.841G > C p.(Asp281His) } \\
\text { 39\% reads. }\end{array}$ & ACC6 & $\mathrm{ACC}$ & $\begin{array}{c}\text { CTNNB1 c. } 134 \mathrm{C}>\mathrm{T} \text { p.(Ser45Phe }) \\
23 \% \text { reads }\end{array}$ \\
\hline SDC50 & SDC & $\begin{array}{c}\text { TP53 c.377_380delACTC } \\
\text { p.(Tyr126SerfsTer43) 18\% reads }\end{array}$ & & & \\
\hline SDC52 & SDC & $\begin{array}{c}\text { TP53 c.626_627delGA } \\
\text { p.(Arg209LysfsTer6) 43\% reads }\end{array}$ & & & \\
\hline SDC53 & SDC & TP53 c. 919 + 1G > C $25 \%$ reads & & & \\
\hline SDC54 & SDC & $\begin{array}{c}\text { TP53 c.650T > G p.(Val217Gly) } \\
15 \% \text { reads }\end{array}$ & & & \\
\hline SDC55 & SDC & $\begin{array}{c}\text { TP53 c.452C > G p.(Pro151Arg) } \\
21 \% \text { reads }\end{array}$ & & & \\
\hline SDC56 & SDC & $\begin{array}{c}\text { TP53 c.912delT } \\
\text { p.(Lys305SerfsTer40) 17\% reads }\end{array}$ & & & \\
\hline
\end{tabular}

\subsubsection{PIK3CA/AKT/PTEN}

In total, 50\% (8/16) of patients with SDC had mutations in PIK3CA/AKT/PTEN, conferring the hyperactivation of the PI3K signalling pathway. In ACC, the frequency was $5 \%(6 / 115)$. In PIK3CA, 12 gain-of-function variants were detected in 11 patients (Table 3). As such, 2/115 ACC patients (2\%) could have been matched to trials based on their PIK3CA mutation status with level $2 \mathrm{~b}$ evidence. Level $2 \mathrm{~b}$ was attributed to PIK3CA mutations based on preliminary data published from basket trials including PI3K inhibitors, showing a response rate of $16 \%$ and stable disease rate of $66 \%$ at 6 months in patients with tumours harbouring PIK3CA mutations [38]. The utility of PIK3CA rises to $14 \%(9 / 63)$ when applied to nonadenoid cystic salivary gland cancer and to $37 \%(6 / 16)$ for patients with salivary duct carcinoma. However, in non-ACC SGC, the evidence level is 3 a based on the efficacy of PIK3CA inhibitors in breast cancer [43]. One case of apelisib plus androgen deprivation in SDC is reported, resulting in significant benefits [44].

AKT1 gain-of-function (E17K) variants were identified in 1\% (1/115) of ACC and 13\% $(2 / 16)$ of SDC patients. AKT1 inhibitors have shown higher response rates in a basket trial in patients with AKT1 E17K-mutated tumours; however, no SGC patients were included in this trial and they are, therefore, ranked as $3 a$.

Loss-of-function PTEN variants were observed in 3\% (4/115) of ACC patients and $3 \%(2 / 63)$ of non-ACC SGC patients. Clinical responses have been seen in the early phase trials of PI3Kb inhibitors in tumours with PTEN loss in prostate cancer [39] and gastric cancer [45], giving PTEN a 3a ranking.

\subsubsection{Receptor Tyrosine Kinases-ERBB2 and EGFR}

Pathogenic ERBB2 mutations were identified in three patients with salivary gland cancer (Table 3), which provides a match to trial therapies with level 3a/3b evidence. Level $3 b$ is applied to SDC as there is evidence of efficacy of anti-HER2 therapy in HER2-amplified 
SDCs [13] and in other SGC subtypes. It was classified as 3a as a result of the efficacy of anti-HER2 therapies in lung cancer patients with gain-of-function mutations [46]. Again, this alteration was most frequent in patients with salivary duct carcinoma $(2 / 16,13 \%)$.

EGFR was mutated in one patient with adenoid cystic carcinoma (Table 3). The variant was c.2369C > T p.(Thr790Met), which is a commonly acquired variant that confers resistance to most EGFR tyrosine kinase inhibitors, but is sensitive to Osimertinib [30]. This matched these patients to trial therapies with level 3a evidence due to the efficacy data for non-small-cell lung cancer.

\subsubsection{Others-BRAF, KRAS and CTNNB1}

Two BRAF alterations were identified in patients with adenoid cystic carcinoma and salivary duct carcinoma (Table S2). Both were class 3 gain-of-function mutations. Class 3 BRAF mutations are characterized by a dependence on RAS signalling and are hypothesized to be sensitive to RAS inhibition. While BRAF V600E would be classified as 3a, BRAF class 3 mutations are classed as $\mathrm{X}$ as they have no kinase activity themselves and are dependant on upstream oncogenic signalling and commonly co-occur with NF1 deletions [47]. A single KRAS mutation was identified in a patient with an adenocarcinoma; this missense mutation resulted in KRAS gain of function. The variant identified was not G12C and, as such, there is only preclinical evidence of increased sensitivity to MEK/ERK inhibitors. Thus, this variant was classified as 4a [36].

CTNNB1 codes for beta-catenin: One variant in an ACC patient was detected. Preclinical data have shown CTNNB1 variants to confer increased sensitivity to CBP/Betacatenin inhibitors, and so this variant was therefore classed as 4a [28].

\subsection{Biomarker-Matched Trial Availability}

Through the course of this study, using the 24-gene panel, 7\% (8/115) of ACC patients could be matched to a biomarker-led clinical trial based on the molecular screening results. In $6 \%(7 / 115)$ of cases, this was due to variants conferring the hyperactivation of the PI3K pathway (AKT1, PIK3CA and PTEN variants), who could be treated with AKT1 inhibitors, such as Capivasertib (NCT0122631, NCT02338622). The remaining ACC match was for a patient with an EGFR mutation, who could have been matched to AFM24 (NCT04259450).

In SDC, $63 \%(10 / 16)$ could be matched to biomarker-led trials. A total of 50\% (8/16) were, again, matched to AKT1 inhibitors such as Capivasertib and 13\% $(2 / 16)$ to HER-2 inhibitors such as Neratinib (NCT01953926) or TAS0728 (NCT03410927).

Matched trial therapies were available for $20 \%$ (3/15) of patients with adenocarcinoma (NOS), 13\% (2/15) to AKT1 inhibitors (NCT01226316, NCT02338622) and 7\% (1/15) to RAF/MEK inhibitors, based on a KRAS mutation through NCT02407509. The relatively small number of patients included with other non-ACC subtypes limits the analysis. However, matched trial therapies were available for $25 \%(2 / 8)$ of patients with carcinoma ex-pleomorphic adenoma, 20\% (1/8) with acinic cell carcinoma, and 16\% (1/6) with mucoepidermoid carcinoma.

\subsection{Next-Generation Sequencing with 350+ Gene Targeted Panel}

As $81 \%$ of ACC patients (94/115) had no genetic alterations identified with the 24-gene panel, we next sought to determine the additional utility of applying a broader NGS panel in this cohort. We, therefore, re-analysed the FFPE tumour samples from $32 \mathrm{ACC}$ patients in whom no variants had been detected on the focused NGS panels using a commercially available ( $>325$-gene) NGS panel. Additional genomic findings were detected in 27/32 patients (84\%). Figure 2 summarises the genetic alterations identified through this approach, and the full list of variations can be found in Supplementary Table S2. ESCAT scores were allocated to genes where a variant was detected; references can be found on Supplementary Table S2. 


\begin{tabular}{|c|c|c|c|c|c|c|c|}
\hline Pathway & \multicolumn{3}{|c|}{ Gene and freqencey } & ESCAT & Drug (Targeted pathway) & \begin{tabular}{|c|}
$\begin{array}{c}\text { Open Biomarker } \\
\text { selected trials }\end{array}$ \\
\end{tabular} & $\begin{array}{c}\text { Non-Biomarker } \\
\text { selected trials }\end{array}$ \\
\hline Telomere Maintenance & \multicolumn{3}{|c|}{ 22\% HHHH|||||||||||||||||||||||||||||| } & $x$ & $x$ & $x$ & $x$ \\
\hline Transcription Regulation & MYB-NFIB & \multicolumn{2}{|c|}{ 22\% } & $4 a$ & ATR inhibitor & $x$ & NCT62223929 \\
\hline Transcription Regulation & BCOR & ${ }_{19 \%}$ |||||||||| & |H+||||||||||||||||||| & $x$ & $x$ & $x$ & $x$ \\
\hline Transcription Regulation & EP300 & $19 \%$ & H|| & $4 a$ & EP300/CBP inhibitor & NCT03568656 & $x$ \\
\hline Transcription Regulation & CREBBP & 3\% \|\|\|\| & $\|$ & $4 a$ & EP300/CBP inhibitor & NCT03568656 & $x$ \\
\hline Transcription Regulation & ARID1A & ${ }_{13} \%\|\|\|\|$ & H & $4 a$ & EP300/CBP inhibitor & NCT03568656 & $x$ \\
\hline Transcription Regulation & KDM6A & $9 \% \|$ & $|\mathbf{H}||||||| \mid$ & $4 a$ & $\mathrm{EZH} 2$ inhibitors & & NCT03010982 \\
\hline Transcription Regulation & SMARCB1 & 3\% \|\|\|\| & |म||- & $4 a$ & EZH2 inhibitors & NCT02601950 & $x$ \\
\hline Transcription Regulation & SETD2 & 3\% \|\|\|\|$\|$ & \|\|$\|||||||$ & $4 a$ & Wee1 Inhibitor & $x$ & NCT03315091 \\
\hline Cell Signalling & NOTCH1 & ${ }_{13}^{13}\|\|\|\| \|$ & ||||||||||||| & $4 a$ & NOTCH Inhibitors & NCT03691207 & $x$ \\
\hline Cell Signalling & PIK3R1 & ${ }_{13} \%$ ||||||||| & $\| \mathbf{n}|| \mathbf{n}||$ & $4 a$ & AKT1 Inhibitors & NCT02338622 & $x$ \\
\hline Cell Signalling & PTEN & 3\% ||||||||| & & $3 a$ & AKT1 Inhibitors & NCT02338622 & $x$ \\
\hline Cell Signalling & MET & 3\% \|\|\|\|\|\||| & |\|\||| & $3 a$ & MET inhibitors & NCT03175224 & $x$ \\
\hline Cell Signalling & ERBB2 & 3\% \|\|\|\|\|\| $\mid$ & ||||||||||||||| & $3 a$ & HER2 Inhibitors & NCT01953926 & $x$ \\
\hline Spliceosome & SF3B1 & 9\% \|\|\|\|$\| H$ & 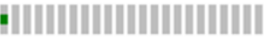 & $4 a$ & SF3B1 inhibitors & $x$ & $x$ \\
\hline Cell Cycle & CDKN2A & 3\% \|\|\|\|$|\|| \mid$ & || & $4 a$ & CDK4/6 inhibitor & $x$ & NCT02389842 \\
\hline Cell Cycle & CDKN2B & 3\% \|\|\|\| $\mid \|$ & | & $4 a$ & CDK4/6 inhibitor & $x$ & NCT02389842 \\
\hline Cell Cycle & CDK6 & 3\% \|\|\|\|$\|$ & |||| & $x$ & $x$ & $x$ & $x$ \\
\hline DNA Damage Repair & ATM & 3\% $\quad\|\|\|\|\|\|$ & $|\|||| \mid$ & $3 a$ & PARP inhibitor & NCT04170153 & $x$ \\
\hline DNA Damage Repair & BARD1 & 3\% \|\|\|\|\|\| $\mid$ & ||||||||||||||||||| & $3 a$ & PARP inhibitor & $x$ & NCT02338622 \\
\hline DNA Damage Repair & RAD51B & 3\% \|\|\|\| & \|\| & $3 a$ & PARP inhibitor & $x$ & NCT02338622 \\
\hline
\end{tabular}

Figure 2. Results of 325-gene NGS panel in patients where no mutation was found in the focused NGS panel. Studies providing the rationale behind ESCAT classification can be found in Supplementary Table S2 [37,39,48-59]. Selected mutations are included in the figure, including all mutations with biomarker-stratified trials; the full list is in Supplementary Table S3.

Additional utility was gained in $40 \%$ (13/32) of patients with regard to being able to match them to a biomarker-stratified clinical trial.

MYB-NFIB fusions and TERT promoter mutations were the most common alterations, with $22 \%(7 / 32)$ and $22 \%(7 / 32)$, respectively. There are no current compounds being developed to target TERT promoter mutations. MYB overexpression as a result of fusion transcripts is the hallmark of ACC, ATR has been shown to be downstream of MYB and in preclinical studies of ACC models, treatment with ATR inhibitors has led to apoptosis and growth inhibition [48].

Genes coding for chromatin modifiers (EP300, ARID1A, KDM6A, BCOR, CREBBP, SETD2, SMARCB1) were altered in 44\% (14/32) of patients, with 13\% (4/32) having more than one gene altered. EP300/CREBBP inhibitors are being trialled in EP300-, ARID1Aand CREBBP-deficient tumours [49].

NOTCH1 was altered in 13\% (4/32), and in three cases these were activating mutations. These can be targeted by gamma secretase inhibitors, which are in phase 2 trials in ACC. AL101 achieved a response rate of $9 \%$ with a disease control rate of $70 \%$; this currently fails to meet the ESMO Magnitude of Clinical Benefit Scale criteria and as such cannot be placed in tier $1 \mathrm{~b}$. As there are no data in ACC outside of NOTCH mutant patients, we cannot comment on there being a higher response rate in this setting (2b). As such, this match was given a rank of $4 \mathrm{a}[50,60]$.

PIK3R1 was mutated in 13\% (4/32) and has been shown to cause hyperactivation of the PI3K pathway [45], indicating a potential role for AKT1 inhibition. In total, 9\% (3/32) had alterations in genes involved in the DNA damage repair pathway that are thought to sensitize one to PARP inhibitors [51].

Previously undetected alterations in MET, ERBB2 and PTEN were detected, even though these genes were included in the primary analysis with the 24-gene panel. The alteration in MET was an amplification, which would not be detected by the 24-gene panel. The ERBB2 mutation was detected in the 24-gene panel but was not identified as being 
significant; this reflects the fact that there may be disagreement in approaches to variant calling. Finally, the PTEN alteration used in the secondary analysis used a tumour sample from a metastatic site, whereas the initial analysis in which this was not detected used a different sample from a primary site. This observation reflects the potential for discordance between mutations identified from primary and metastatic sites.

\section{Discussion}

This study sought to evaluate the clinical utility of tumour profiling by DNA-based NGS when applied to a cohort of patients with recurrent or metastatic salivary gland cancer being evaluated for clinical trials. We found, using a focused (24-gene) NGS panel, that genomic alterations were identified in $27 \%$ of patients with potential biomarker-matched clinical trial therapies available for $14 \%(25 / 175)$. The utility of this approach in identifying matched trial therapies was lower for ACC (7\%) compared with other histological subtypes $(30 \%)$, with the greatest utility seen for salivary duct carcinoma (69\%). For ACC, broader (>325-gene) NGS panels provided additional utility in identifying matched clinical trial therapies, identifying matched trial therapies in $40 \%$ of patients in whom no alterations were identified using the focused panel. For this, we used a predesigned commercially available platform that is clinically and analytically validated for all solid tumours and has FDA approval as a companion diagnostic.

The 24-gene panel utilized was developed for pan-tumour use, in line with the United Kingdom National Genomic Test Directory for somatic mutations in adult solid tumours. This study found that $62 \%(15 / 24)$ of genes in our focused NGS panel are currently being investigated for their potential value as predictive biomarkers in ongoing trials in the UK. A total of $50 \%(12 / 24)$ of these genes are recognised by the FDA as predictive biomarkers or standard-of-care, and as positive predictive biomarkers of response in other tumour types other than salivary gland cancer. In this study, we used the ESMO Scale for Clinical Actionability of Molecular Targets (ESCAT) to determine the level of evidence supporting the match between genomic alteration and drug trial therapy. ESCAT breaks down evidence based on trial types, with prospective trials being evidence level 1, and this is further subdivided based on whether it was randomised (1a), nonrandomised (1b) or a basket trial (1c). Furthermore, ESCAT takes into account whether there was a benefit to overall survival (1a) or overall response rate (2b) [22]. Similar scoring systems such as OncoKB can be more ambiguous on these counts, placing a heavier focus on drug and biomarker approval for use, with nonapproved drugs being classified as "showing clinical benefit". OncoKB provides a web-based resource which allocates biomarker evidence levels automatically; however, this is of more utility in common cancers, and only provides an outline as not all genes are currently included [21].

Mutations in TP53 and PIK3CA were the most frequently identified findings in this cohort. Pathogenic TP53 mutations were the most prevalent alteration identified in our focused panel, being present in 19\% (34/175) of our cohort. We have previously shown TP53 mutation to be a negative prognostic factor in ACC [61]. There have, however, been no SGC specific studies investigating the predictive significance of TP53 mutations. Preclinical studies in cell lines other than SGC showed increased response rates to Wee1 inhibitors [62], but this has yet to translate into the clinic. An NCI-MPACT study, which was open to all solid tumour types, including SGC, investigated the Wee1 inhibitor Adavosertib in combination with carboplatin in a TP53-mutant cohort, but reported no significant responses [63]. Studies on ACC models have indicated that ATR inhibitors may have some benefit in ACC as ATR is downstream of MYB [48], paired with data from preclinical studies in other tumour types that have demonstrated that treatment with ATR inhibitors in TP53mutant tumours results in increased radiotherapy and chemotherapy sensitisation [42], providing a rationale for the enrolling patients whose tumours harbour TP53 mutations in trials such as NCT03669601. However, there are more recent counterbalancing data that indicate that radiosensitisation is independent of TP53 [64]. 
PIK3CA was the second most prevalent finding, with 11/175 patients having mutations conferring increased activity. While there have been no clinical trials investigating PI3K specifically in SGC, six ACC patients were treated with PI3K inhibitors within basket trials: $5 / 6$ patients had stable disease at 2 months, while one patient had a partial response by RECIST 1.1 criteria. It is, however, difficult to draw many conclusions due to the small sample size and very limited follow up reported [38]. There have been no SGC-specific preclinical studies demonstrating the predictive significance of PIK3CA mutation status. PIK3CA is an established predictive biomarker for treatment with Alpelisib plus fulvestrant in hormone receptor-positive breast cancer. Alpelisib as a monotherapy in PIK3CA mutated breast cancer did not show significant clinical benefit [65]. Trials of AKT1 inhibitors are also recruiting patients with activated PIK3CA (NCT NCT01226316, NCT02338622); these are also recruiting patients with PTEN loss, and with AKT1 mutations.

Although biomarker-led drug therapies are providing treatment options for patients with salivary gland cancers, this further subdivision of histopathological entities on the basis of molecular profiling exacerbates the challenges related to the rare nature of salivary cancers. Further subdividing an already small population for trial recruitment may pose a significant problem in obtaining adequate patient numbers to determine true benefits.

Some of the most clinically meaningful changes associated with biomarker-directed therapy development have been reported in HER2-overexpressing/ERBB2-amplified salivary duct carcinoma with HER2-targeted therapies $[6,10,11]$. Now, there is clear evidence of efficacy in the recurrent or metastatic setting, and ongoing trials are now evaluating HER2-targeted therapy as an adjuvant to surgery in the curative setting (NCT04620187 [6]). In addition, in recurrent or metastatic androgen receptor-overexpressing salivary duct carcinoma, now there is clear evidence of clinical benefit from androgen deprivation therapy [7] or combined androgen blockade [8]; there is also an emerging rationale for a clinical trial of $\mathrm{ADT} / \mathrm{CAB}$ in the adjuvant setting for AR-overexpressing salivary duct carcinoma at high risk of disease recurrence.

Within ACC, NOTCH-activating mutations are a promising target; however, gamma secretase inhibitors such as AL101 have yet to show significant clinical benefit, being characterised by the EMSO magnitude of clinical benefit scale. However, the medium- and long-term outcomes of the phase 2 study (NCT03691207) are yet to be published. AL101 had an OR of $14 \%$ and a disease control rate (DCR) of $68 \%$ [50,60]. In NOTCH-activated ACC, which carries a significantly worse prognosis than NOTCH wildtype ACC $[66,67]$ this DCR may translate into a meaningful clinical benefit.

In addition to genomic alterations that have current clinical utility, we have also described alterations which are currently classed as level $X$, meaning there is a lack of evidence of actionability. TERT promoter mutations were classified as $X$, and were found in $22 \%$ of ACC patients sequenced with the extended panel. While it provides no current benefit for treatment selection, previous studies have shown TERT to be a positive prognostic factor [23]. BCOR was similarly classified as X; however, BCOR is frequently mutated in haematological malignancies [68] and, as such, is likely to be investigated further and may become targetable in the future. As the median survival for recurrent or metastatic ACC is in excess of 5 years, it is not inconceivable that BCOR-targeting therapies could be in the clinic in that timeframe.

In this study, tumour tissue was analysed from either metastatic deposits or sites of local recurrence collected as part of their routine diagnostic or treatment. However, analysis from a single biopsy from a primary tumour or of a single metastatic site does not reliably cover the expected intra-patient tumour heterogeneity. For future studies, one approach to increase the likelihood of capturing intra-patient heterogeneity would be to include multiple biopsies or multiple time-points from individual patients. The sequencing of circulating tumour DNA (ctDNA) has been shown to be viable in the clinical setting with good concordance in variant calling with matched tumour samples. For example, the UK TARGET study identified actionable mutations in $41 \%(41 / 100)$ of patients through this method in a mixed cancer cohort, $25 \%(11 / 41)$ of which were treated in matched 
clinical trials (Rothwell et al.). Future prospective studies are planned in SGC which utilise sequencing of (ctDNA) to provide a minimally invasive and "current" picture of variants [69].

Furthermore, tissue samples for analysis were requested to meet the minimum tumour content of $20 \%$ for analyses, for which our panel was validated to detect a variant allele frequency of $4 \%$. However, the exact tumour content of samples was not routinely recorded for all cases which we recognize as a limitation of this study. Although the risk of omitting internal validation of tumour content is the under-calling of mutations through sequencing of an increased percentage of normal tissue DNA, our detected frequencies are however in line with publicly available datasets $[19,20]$.

While we focused on NGS though targeted gene panels within our study, whole genome (WGS) and whole exome sequencing (WES) could also be utilized in this setting. There is potential additional utility using these approaches to identify broader mutation signatures. WGS and WES also provide greater coverage capturing mutations in areas that may become clinically significant as our understanding of the underlying tumour biology increases. However, the additional data generated by WGS/WES approaches due to this broader coverage and additional sequencing steps, through sequencing matched normal DNA, require additional bioinformatics analyses. This plus the additional analytical reagents required make WGS and WES more expensive than targeted NGS panels. This contrasts with targeted NGS panels covering specific clinically important coding and noncoding regions. As such, required read depths can be achieved with minimal reagents and can be interpreted with simpler bioinformatics pipelines; however, this is at the cost of a limitation of utility for broader discovery research. The impact of mutations in genes involved in epigenetic regulation such as BCOR, can be difficult to predict due to the myriad of pathways that are regulated through epigenetics. Microarrays can be used for detecting variations in gene expression levels. This could be explored in future analyses to assess the impact of detected somatic mutations on the transcriptome. While BCOR is not currently targetable, mutations in this gene may result in overexpression a targetable protein.

A further barrier to the clinical application of the genomic findings is the limited availability of clinical trials recruiting in the UK. Relatively few sites are actively recruiting to each individual trial providing a practical or geographical barrier to clinical trial recruitment. For example, there were no available clinical trials accepting salivary gland cancer patients for the approved anti-EGFR therapies, such as afatinib and erlotinib or osimertinib within the UK. The UK is lacking a large tumour-agnostic trial such as NCIMATCH(NCT02465060) or CAPTUR (NCT03297606). However, this situation may improve as the TAPISTRY trial (NCT04589845) is set to open for recruitment in the UK, enabling access to a selection of matched trial therapies.

The success of NTRK-targeted therapies in patients with secretory carcinoma harbouring NTRK gene fusions represents a significant step forward for genetic based approaches in SGC. These patients were not represented in our cohort, possibly due to the lower frequency of recurrence in this subtype in comparison to other salivary gland cancer types [70].

\section{Conclusions}

Tumour profiling with targeted DNA panels provides valuable information to help provide a rationale for enrolling patients in early phase trials. This approach showed the most utility in salivary duct carcinoma. Expanded sequencing with $>325$-gene panels provided added utility in ACC and identified the deregulation of transcriptional regulation with EP300, KDM6A and ARID1A mutations, in addition to the classically reported MYB translocations.

Supplementary Materials: The following supporting information can be downloaded at: https:// www.mdpi.com/article/10.3390/cancers14051133/s1, Table S1: panel coverage, Table S2: ESCAT ref, Table S3: Variants. 


\begin{abstract}
Author Contributions: Conceptualization, R.M. and S.R. methodology, R.M. and S.R.; formal analysis, S.R. and L.W.; resources, R.M.; data curation, S.R., L.F., H.A., B.H., L.W., G.J.B., K.J.H., G.B. and R.M.; writing—original draft preparation, S.R.; writing-review and editing, S.R. and R.M.; visualization, S.R.; supervision, R.M.; funding acquisition, R.M. All authors have read and agreed to the published version of the manuscript.
\end{abstract}

Funding: This research was funded by Syncona Foundation, The Harriet Bowman Foundation, The Infrastructure Industry Foundation and The Christie Charity.

Institutional Review Board Statement: The study was granted research ethics approval under the MCRC Biobank Research Tissue Bank Ethics (NHS NW Research Ethics Committee 18/NW/0092) and was performed in accordance with the Declaration of Helsinki. The role of the MCRC Biobank is to distribute samples and, therefore, cannot endorse studies performed or the interpretation of results.

Informed Consent Statement: All subjects provided informed consent to the collection of demographic, clinical, and genomic data included in this study.

Data Availability Statement: The data presented in this study are available on request from the corresponding author. The data are not publicly available due to the requirement to uphold the data sharing with relevant approved researchers as stipulated in the ethical approval.

Acknowledgments: The authors are grateful for the assistance of Jenni Hill and Lesley Drain for their support in co-ordinating the NGS analyses for this study.

Conflicts of Interest: The authors declare no conflict of interest.

\title{
References
}

1. Lin, H.H.; Limesand, K.H.; Ann, D.K. Current State of Knowledge on Salivary Gland Cancers. Crit. Rev. Oncog. 2018, 23, 139-151. [CrossRef] [PubMed]

2. Di Villeneuve, L.; Souza, I.L.; Tolentino, F.D.S.; Ferrarotto, R.; Schvartsman, G. Salivary Gland Carcinoma: Novel Targets to Overcome Treatment Resistance in Advanced Disease. Front. Oncol. 2020, 10, 2097. [CrossRef] [PubMed]

3. Chintakuntlawar, A.V.; Okuno, S.H.; Price, K.A. Systemic Therapy for Recurrent or Metastatic Salivary Gland Malignancies. Cancers Head Neck 2016, 1, 11. [CrossRef]

4. Doebele, R.C.; Drilon, A.; Paz-Ares, L.; Siena, S.; Shaw, A.T.; Farago, A.F.; Blakely, C.M.; Seto, T.; Cho, B.C.; Tosi, D.; et al. Entrectinib in Patients with Advanced or Metastatic NTRK Fusion-Positive Solid Tumours: Integrated Analysis of Three Phase 1-2 Trials. Lancet Oncol. 2020, 21, 271-282. [CrossRef]

5. $\quad$ Drilon, A.; Laetsch, T.W.; Kummar, S.; DuBois, S.G.; Lassen, U.N.; Demetri, G.D.; Nathenson, M.; Doebele, R.C.; Farago, A.F.; Pappo, A.S.; et al. Efficacy of Larotrectinib in TRK Fusion-Positive Cancers in Adults and Children. N. Engl. J. Med. 2018, 378, 731-739. [CrossRef] [PubMed]

6. Hanna, G.J.; Bae, J.E.; Lorch, J.H.; Haddad, R.I.; Jo, V.Y.; Schoenfeld, J.D.; Margalit, D.N.; Tishler, R.B.; Goguen, L.A.; Annino, D.J., Jr.; et al. The Benefits of Adjuvant Trastuzumab for HER-2-Positive Salivary Gland Cancers. Oncology 2020, 25, 598-608. [CrossRef] [PubMed]

7. Viscuse, P.V.; Price, K.A.; Garcia, J.J.; Schembri-Wismayer, D.J.; Chintakuntlawar, A.V. First Line Androgen Deprivation Therapy vs. Chemotherapy for Patients With Androgen Receptor Positive Recurrent or Metastatic Salivary Gland Carcinoma-A Retrospective Study. Front. Oncol. 2019, 9, 701. [CrossRef]

8. Fushimi, C.; Tada, Y.; Takahashi, H.; Nagao, T.; Ojiri, H.; Masubuchi, T.; Matsuki, T.; Miura, K.; Kawakita, D.; Hirai, H.; et al. A Prospective Phase II Study of Combined Androgen Blockade in Patients with Androgen Receptor-Positive Metastatic or Locally Advanced Unresectable Salivary Gland Carcinoma. Ann. Oncol. 2018, 29, 979-984. [CrossRef]

9. Ho, A.L.; Foster, N.R.; Zoroufy, A.J.; Worden, F.P.; Price, K.A.R.; Adkins, D.; Bowles, D.W.; Kang, H.; Burtness, B.; Sherman, E.J.; et al. Alliance A091404: A Phase II Study of Enzalutamide (NSC\# 766085) for Patients with Androgen Receptor-Positive Salivary Cancers. J. Clin. Oncol. 2019, 37, 6020. [CrossRef]

10. Li, B.T.; Shen, R.; Offin, M.; Buonocore, D.J.; Myers, M.L.; Venkatesh, A.; Razavi, P.; Ginsberg, M.S.; Ulaner, G.A.; Solit, D.B.; et al. Ado-Trastuzumab Emtansine in Patients with HER2 Amplified Salivary Gland Cancers (SGCs): Results from a Phase II Basket Trial. J. Clin. Oncol. 2019, 37, 6001. [CrossRef]

11. Takahashi, H.; Tada, Y.; Saotome, T.; Akazawa, K.; Ojiri, H.; Fushimi, C.; Masubuchi, T.; Matsuki, T.; Tani, K.; Osamura, R.Y.; et al. Phase II Trial of Trastuzumab and Docetaxel in Patients With Human Epidermal Growth Factor Receptor 2-Positive Salivary Duct Carcinoma. J. Clin. Oncol. 2018, 37, 125-134. [CrossRef] [PubMed]

12. Kurzrock, R.; Bowles, D.W.; Kang, H.; Meric-Bernstam, F.; Hainsworth, J.; Spigel, D.R.; Bose, R.; Burris, H.; Sweeney, C.J.; Beattie, M.S.; et al. Targeted Therapy for Advanced Salivary Gland Carcinoma Based on Molecular Profiling: Results from MyPathway, a Phase IIa Multiple Basket Study. Ann. Oncol. 2020, 31, 412-421. [CrossRef] [PubMed] 
13. Uijen, M.J.M.; Lassche, G.; van Engen-van Grunsven, A.C.H.; Tada, Y.; Verhaegh, G.W.; Schalken, J.A.; Driessen, C.M.L.; van Herpen, C.M.L. Systemic Therapy in the Management of Recurrent or Metastatic Salivary Duct Carcinoma: A Systematic Review. Cancer Treat. Rev. 2020, 89. [CrossRef] [PubMed]

14. Xu, B.; Haroon Al Rasheed, M.R.; Antonescu, C.R.; Alex, D.; Frosina, D.; Ghossein, R.; Jungbluth, A.A.; Katabi, N. Pan-Trk Immunohistochemistry Is a Sensitive and Specific Ancillary Tool for Diagnosing Secretory Carcinoma of the Salivary Gland and Detecting ETV6-NTRK3 Fusion. Histopathology 2020, 76, 375-382. [CrossRef]

15. Kato, S.; Elkin, S.K.; Schwaederle, M.; Tomson, B.N.; Helsten, T.; Carter, J.L.; Kurzrock, R. Genomic Landscape of Salivary Gland Tumors. Oncotarget 2015, 6, 25631-25645. [CrossRef]

16. Garrett, A.; Callaway, A.; Durkie, M.; Cubuk, C.; Alikian, M.; Burghel, G.J.; Robinson, R.; Izatt, L.; Talukdar, S.; Side, L.; et al. Cancer Variant Interpretation Group UK (CanVIG-UK): An Exemplar National Subspecialty Multidisciplinary Network. J. Med. Genet. 2020, 57, 829-834. [CrossRef]

17. Li, M.M.; Datto, M.; Duncavage, E.J.; Kulkarni, S.; Lindeman, N.I.; Roy, S.; Tsimberidou, A.M.; Vnencak-Jones, C.L.; Wolff, D.J.; Younes, A.; et al. Standards and Guidelines for the Interpretation and Reporting of Sequence Variants in Cancer: A Joint Consensus Recommendation of the Association for Molecular Pathology, American Society of Clinical Oncology, and College of American Pathologists. J. Mol. Diagn. JMD 2017, 19, 4-23. [CrossRef]

18. Frampton, G.M.; Fichtenholtz, A.; Otto, G.A.; Wang, K.; Downing, S.R.; He, J.; Schnall-Levin, M.; White, J.; Sanford, E.M.; An, P.; et al. Development and Validation of a Clinical Cancer Genomic Profiling Test Based on Massively Parallel DNA Sequencing Nat. Biotechnol. 2013, 31, 1023-1031. [CrossRef] [PubMed]

19. Gao, J.; Aksoy, B.A.; Dogrusoz, U.; Dresdner, G.; Gross, B.; Sumer, S.O.; Sun, Y.; Jacobsen, A.; Sinha, R.; Larsson, E.; et al. Integrative Analysis of Complex Cancer Genomics and Clinical Profiles Using the CBioPortal. Sci. Signal. 2013, 6, pl1. [CrossRef]

20. Cerami, E.; Gao, J.; Dogrusoz, U.; Gross, B.E.; Sumer, S.O.; Aksoy, B.A.; Jacobsen, A.; Byrne, C.J.; Heuer, M.L.; Larsson, E.; et al The CBio Cancer Genomics Portal: An Open Platform for Exploring Multidimensional Cancer Genomics Data. Cancer Discov. 2012, 2, 401. [CrossRef]

21. Chakravarty, D.; Gao, J.; Phillips, S.M.; Kundra, R.; Zhang, H.; Wang, J.; Rudolph, J.E.; Yaeger, R.; Soumerai, T.; Nissan, M.H.; et al. OncoKB: A Precision Oncology Knowledge Base. JCO Precis. Oncol. 2017, 1, 1-16. [CrossRef] [PubMed]

22. Mateo, J.; Chakravarty, D.; Dienstmann, R.; Jezdic, S.; Gonzalez-Perez, A.; Lopez-Bigas, N.; Ng, C.K.Y.; Bedard, P.L.; Tortora, G.; Douillard, J.-Y.; et al. A Framework to Rank Genomic Alterations as Targets for Cancer Precision Medicine: The ESMO Scale for Clinical Actionability of Molecular Targets (ESCAT). Ann. Oncol. 2018, 29, 1895-1902. [CrossRef] [PubMed]

23. Marcinow, A.; Ozer, E.; Teknos, T.; Wei, L.; Hurtuk, A.; Old, M.; Agrawal, A.; Carrau, R.; Iwenofu, O.H. Clinicopathologic Predictors of Recurrence and Overall Survival in Adenoid Cystic Carcinoma of the Head and Neck: A Single Institutional Experience at a Tertiary Care Center. Head Neck 2014, 36, 1705-1711. [CrossRef] [PubMed]

24. Kalinsky, K.; Hong, F.; McCourt, C.K.; Sachdev, J.C.; Mitchell, E.P.; Zwiebel, J.A.; Doyle, L.A.; McShane, L.M.; Li, S.; Gray, R.J.; et al. Effect of Capivasertib in Patients with an AKT1 E17K-Mutated Tumor: NCI-MATCH Subprotocol EAY131-Y Nonrandomized Trial. JAMA Oncol. 2021, 7, 271-278. [CrossRef]

25. Jernberg, E.; Bergh, A.; Wikström, P. Clinical Relevance of Androgen Receptor Alterations in Prostate Cancer. Endocr. Connect. 2017, 6, R146-R161. [CrossRef] [PubMed]

26. Shaw, A.T.; Solomon, B.J.; Besse, B.; Bauer, T.M.; Lin, C.-C.; Soo, R.A.; Riely, G.J.; Ou, S.-H.I.; Clancy, J.S.; Li, S.; et al. ALK Resistance Mutations and Efficacy of Lorlatinib in Advanced Anaplastic Lymphoma Kinase-Positive Non-Small-Cell Lung Cancer. J. Clin. Oncol. 2019, 37, 1370-1379. [CrossRef]

27. Dankner, M.; Lajoie, M.; Moldoveanu, D.; Nguyen, T.-T.; Savage, P.; Rajkumar, S.; Huang, X.; Lvova, M.; Protopopov, A.; Vuzman, D.; et al. Dual MAPK Inhibition Is an Effective Therapeutic Strategy for a Subset of Class II BRAF Mutant Melanomas. Clin. Cancer Res. 2018, 24, 6483. [CrossRef]

28. Zaman, G.J.R.; de Roos, J.A.D.M.; Libouban, M.A.A.; Prinsen, M.B.W.; de Man, J.; Buijsman, R.C.; Uitdehaag, J.C.M. TTK Inhibitors as a Targeted Therapy for CTNNB1 Mutant Cancers. Mol. Cancer Ther. 2017, 16, 2609. [CrossRef]

29. Terai, H.; Tan, L.; Beauchamp, E.M.; Hatcher, J.M.; Liu, Q.; Meyerson, M.; Gray, N.S.; Hammerman, P.S. Characterization of DDR2 Inhibitors for the Treatment of DDR2 Mutated Nonsmall Cell Lung Cancer. ACS Chem. Biol. 2015, 10, 2687-2696. [CrossRef]

30. Ramalingam, S.S.; Vansteenkiste, J.; Planchard, D.; Cho, B.C.; Gray, J.E.; Ohe, Y.; Zhou, C.; Reungwetwattana, T.; Cheng, Y.; Chewaskulyong, B.; et al. Overall Survival with Osimertinib in Untreated, EGFR-Mutated Advanced NSCLC. N. Engl. J. Med. 2019, 382, 41-50. [CrossRef]

31. Weaver, A.; Bossaer, J.B. Fibroblast Growth Factor Receptor (FGFR) Inhibitors: A Review of a Novel Therapeutic Class. J. Oncol. Pharm. Pract. 2020, 27, 702-710. [CrossRef] [PubMed]

32. Croce, M.; Ferrini, S.; Pfeffer, U.; Gangemi, R. Targeted Therapy of Uveal Melanoma: Recent Failures and New Perspectives Cancers 2019, 11, 846. [CrossRef] [PubMed]

33. Zhu, A.X.; Macarulla, T.; Javle, M.M.; Kelley, R.K.; Lubner, S.J.; Adeva, J.; Cleary, J.M.; Catenacci, D.V.T.; Borad, M.J.; Bridgewater, J.A.; et al. Final Overall Survival Efficacy Results of Ivosidenib for Patients With Advanced Cholangiocarcinoma With IDH1 Mutation: The Phase 3 Randomized Clinical ClarIDHy Trial. JAMA Oncol. 2021, 7, 1669-1677. [CrossRef] [PubMed]

34. Dogra, R.; Bhatia, R.; Shankar, R.; Bansal, P.; Rawal, R.K. Enasidenib: First Mutant IDH2 Inhibitor for the Treatment of Refractory and Relapsed Acute Myeloid Leukemia. Anti-Cancer Agents Med. Chem. 2018, 18, 1936-1951. [CrossRef] 
35. Heinrich, M.C.; Rankin, C.; Blanke, C.D.; Demetri, G.D.; Borden, E.C.; Ryan, C.W.; von Mehren, M.; Blackstein, M.E.; Priebat, D.A.; Tap, W.D.; et al. Correlation of Long-Term Results of Imatinib in Advanced Gastrointestinal Stromal Tumors With Next-Generation Sequencing Results: Analysis of Phase 3 SWOG Intergroup Trial S0033. JAMA Oncol. 2017, 3, 944-952. [CrossRef]

36. Samatar, A.A.; Poulikakos, P.I. Targeting RAS-ERK Signalling in Cancer: Promises and Challenges. Nat. Rev. Drug Discov. 2014, 13, 928-942. [CrossRef]

37. Wolf, J.; Seto, T.; Han, J.-Y.; Reguart, N.; Garon, E.B.; Groen, H.J.M.; Tan, D.S.W.; Hida, T.; de Jonge, M.; Orlov, S.V.; et al. Capmatinib in MET Exon 14-Mutated or MET -Amplified Non-Small-Cell Lung Cancer. N. Engl. J. Med. 2020, 383, $944-957$. [CrossRef]

38. Ho, A.S.; Ochoa, A.; Jayakumaran, G.; Zehir, A.; Valero Mayor, C.; Tepe, J.; Makarov, V.; Dalin, M.G.; He, J.; Bailey, M.; et al. Genetic Hallmarks of Recurrent/Metastatic Adenoid Cystic Carcinoma. J. Clin. Investig. 2019, 129, 4276-4289. [CrossRef]

39. De Bono, J.; de Giorgi, U.; Massard, C.; Bracarda, S.; Nava Rodrigues, D.; Kocak, I.; Font, A.; Arranz Arija, J.; Shih, K.; Radavoi, G.; et al. PTEN Loss as a Predictive Biomarker for the Akt Inhibitor Ipatasertib Combined with Abiraterone Acetate in Patients with Metastatic Castration-Resistant Prostate Cancer (MCRPC). Ann. Oncol. 2016, 27, vi243. [CrossRef]

40. Klubo-Gwiezdzinska, J. Targeting RET-Mutated Thyroid and Lung Cancer in the Personalised Medicine Era. Lancet Diabetes Endocrinol. 2021, 9, 473-474. [CrossRef]

41. Zhao, R.-X.; Xu, Z.-X. Targeting the LKB1 Tumor Suppressor. Curr. Drug Targets 2014, 15, 32-52. [CrossRef] [PubMed]

42. Reaper, P.M.; Griffiths, M.R.; Long, J.M.; Charrier, J.-D.; MacCormick, S.; Charlton, P.A.; Golec, J.M.C.; Pollard, J.R. Selective Killing of ATM- or P53-Deficient Cancer Cells through Inhibition of ATR. Nat. Chem. Biol. 2011, 7, 428-430. [CrossRef]

43. André, F.; Ciruelos, E.; Rubovszky, G.; Campone, M.; Loibl, S.; Rugo, H.S.; Iwata, H.; Conte, P.; Mayer, I.A.; Kaufman, B.; et al. Alpelisib for PIK3CA-Mutated, Hormone Receptor-Positive Advanced Breast Cancer. N. Engl. J. Med. 2019, 380, 1929-1940. [CrossRef] [PubMed]

44. Sheth, H.; Kumar, P.; Shreenivas, A.; Sambath, J.; Pragya, R.; Madre, C.; Athikari, N.; Khandare, H.; Peshattiwar, V.; Datar, R.; et al. Excellent Response With Alpelisib and Bicalutamide for Advanced Salivary Duct Carcinoma With PIK3CA Mutation and High Androgen Receptor Expression-A Case Report. JCO Precis. Oncol. 2021, 744-750. [CrossRef] [PubMed]

45. Jung, M.; Kim, C.; Kim, H.; Lee, C.; Lee, H.; Bae, W.; Jeung, H.; Zang, D.; Park, S.; Hwang, I.; et al. SO-10 An Open-Label, Multi-Centre, Phase $\mathrm{Ib} / \mathrm{II}$ Study of PI3K $\beta$ Selective Inhibitor GSK2636771 Administered in Combination with Paclitaxel in Patients with Advanced Gastric Cancer Having Alterations in PI3K/Akt Pathway. Ann. Oncol. 2021, 32, s206. [CrossRef]

46. Li, B.T.; Shen, R.; Buonocore, D.; Olah, Z.T.; Ni, A.; Ginsberg, M.S.; Ulaner, G.A.; Offin, M.; Feldman, D.; Hembrough, T.; et al. Ado-Trastuzumab Emtansine for Patients With HER2-Mutant Lung Cancers: Results From a Phase II Basket Trial. J. Clin. Oncol. 2018, 36, 2532-2537. [CrossRef]

47. Yao, Z.; Yaeger, R.; Rodrik-Outmezguine, V.S.; Tao, A.; Torres, N.M.; Chang, M.T.; Drosten, M.; Zhao, H.; Cecchi, F.; Hembrough, T.; et al. Tumours with Class 3 BRAF Mutants Are Sensitive to the Inhibition of Activated RAS. Nature 2017, 548, $234-238$. [CrossRef]

48. Andersson, M.K.; Mangiapane, G.; Nevado, P.T.; Tsakaneli, A.; Carlsson, T.; Corda, G.; Nieddu, V.; Abrahamian, C.; Chayka, O.; Rai, L.; et al. ATR Is a MYB Regulated Gene and Potential Therapeutic Target in Adenoid Cystic Carcinoma. Oncogenesis 2020, 9, 5. [CrossRef]

49. Crabb, S.; Plummer, R.; Greystoke, A.; Carter, L.; Pacey, S.; Walter, H.; Coyle, V.M.; Knurowski, T.; Clegg, K.; Ashby, F.; et al. 560TiP A Phase I/IIa Study to Evaluate the Safety and Efficacy of CCS1477, a First in Clinic Inhibitor of P300/CBP, as Monotherapy in Patients with Selected Molecular Alterations. Ann. Oncol. 2021, 32, S617. [CrossRef]

50. Ferrarotto, R.; Wirth, L.J.; Muzaffar, J.; Rodriguez, C.P.; Xia, B.; Perez, C.A.; Bowles, D.W.; Winquist, E.; Hotte, S.J.; Metcalf, R.; et al. 919MO ACCURACY a Phase II Trial of AL101, a Selective Gamma Secretase Inhibitor, in Subjects with Recurrent/Metastatic (R/M) Adenoid Cystic Carcinoma (ACC) Harboring Notch Activating Mutations (Notchmut). Ann. Oncol. 2020, 31, S663. [CrossRef]

51. De Bono, J.; Mateo, J.; Fizazi, K.; Saad, F.; Shore, N.; Sandhu, S.; Chi, K.N.; Sartor, O.; Agarwal, N.; Olmos, D.; et al. Olaparib for Metastatic Castration-Resistant Prostate Cancer. N. Engl. J. Med. 2020, 382, 2091-2102. [CrossRef] [PubMed]

52. Wang, L.; Shilatifard, A. UTX Mutations in Human Cancer. Cancer Cell 2019, 35, 168-176. [CrossRef] [PubMed]

53. Knutson, S.K.; Warholic, N.M.; Wigle, T.J.; Klaus, C.R.; Allain, C.J.; Raimondi, A.; Porter Scott, M.; Chesworth, R.; Moyer M.P.; Copeland, R.A.; et al. Durable Tumor Regression in Genetically Altered Malignant Rhabdoid Tumors by Inhibition of Methyltransferase EZH2. Proc. Natl. Acad. Sci. USA 2013, 110, 7922-7927. [CrossRef] [PubMed]

54. Pfister, S.X.; Markkanen, E.; Jiang, Y.; Sarkar, S.; Woodcock, M.; Orlando, G.; Mavrommati, I.; Pai, C.-C.; Zalmas, L.-P.; Drobnitzky, N.; et al. Inhibiting WEE1 Selectively Kills Histone H3K36me3-Deficient Cancers by DNTP Starvation. Cancer Cell 2015, 28, 557-568. [CrossRef]

55. Yu, Y.; Hall, T.; Eathiraj, S.; Wick, M.J.; Schwartz, B.; Abbadessa, G. In-Vitro and in-Vivo Combined Effect of ARQ 092, an AKT Inhibitor, with ARQ 087, a FGFR Inhibitor. Anti-Cancer Drugs 2017, 28, 503-513. [CrossRef]

56. Peters, S.; Stahel, R.; Bubendorf, L.; Bonomi, P.; Villegas, A.; Kowalski, D.M.; Baik, C.S.; Isla, D.; Carpeno, J.D.C.; Garrido, P.; et al. Trastuzumab Emtansine (T-DM1) in Patients with Previously Treated HER2-Overexpressing Metastatic Non-Small Cell Lung Cancer: Efficacy, Safety, and Biomarkers. Clin. Cancer Res. 2019, 25, 64-72. [CrossRef]

57. Zhou, Z.; Gong, Q.; Wang, Y.; Li, M.; Wang, L.; Ding, H.; Li, P. The Biological Function and Clinical Significance of SF3B1 Mutations in Cancer. Biomark. Res. 2020, 8, 38. [CrossRef] 
58. Min, A.; Kim, Y.J.; Lee, M.; Lee, K.-H.; Im, S.-A. Abstract PS5-40: CDKN2A Loss Can Be a Predictive Marker of Palbociclib in Breast and Gastric Cancer. Cancer Res. 2021, 81, PS5-40. [CrossRef]

59. Hamilton, E.; Infante, J.R. Targeting CDK4/6 in Patients with Cancer. Cancer Treat. Rev. 2016, 45, 129-138. [CrossRef]

60. Ho, A.L.; Bowles, D.W.; Even, C.; Hao, D.; Kang, H.; Metcalf, R.; Muzaffar, J.; Oliva, M.; Perez, C.A.; Popovtzer, A.; et al. 904P ACCURACY: A Phase II Trial of AL101, a Selective Gamma Secretase Inhibitor, in Subjects with Recurrent/Metastatic (R/M) Adenoid Cystic Carcinoma (ACC) Harboring Notch Activating Mutations (Notchmut): Results of 6-Mg Cohort. Ann. Oncol. 2021, 32, S803-S804. [CrossRef]

61. Adderley, H.; Rack, S.; Hapuarachi, B.; Feeney, L.; Morgan, D.; Hussell, T.; Wallace, A.J.; Betts, G.; Hodgson, C.; Harrington, K.; et al. The Utility of TP53 and PIK3CA Mutations as Prognostic Biomarkers in Salivary Adenoid Cystic Carcinoma. Oral Oncol. 2021, 113, 105095. [CrossRef] [PubMed]

62. Yang, C.; Li, Z.; Li, Q.; Xia, Y.; Chan, C.-C.; Yuan, X.; Wang, Y.; Chen, S.; Qian, W. Preclinical Evaluation of SC0191, a Small Molecule Inhibitor of Wee1 Kinase. J. Clin. Oncol. 2020, 38, e15637. [CrossRef]

63. Chen, A.P.; Kummar, S.; Moore, N.; Rubinstein, L.V.; Zhao, Y.; Williams, P.M.; Palmisano, A.; Sims, D.; O'Sullivan Coyne, G.; Rosenberger, C.L.; et al. Molecular Profiling-Based Assignment of Cancer Therapy (NCI-MPACT): A Randomized Multicenter Phase II Trial. JCO Precis. Oncol. 2021, 133-144. [CrossRef] [PubMed]

64. Dillon, M.T.; Barker, H.E.; Pedersen, M.; Hafsi, H.; Bhide, S.A.; Newbold, K.L.; Nutting, C.M.; McLaughlin, M.; Harrington, K.J. Radiosensitization by the ATR Inhibitor AZD6738 through Generation of Acentric Micronuclei. Mol. Cancer Ther. 2017, 16, 25. [CrossRef]

65. Juric, D.; Rodon, J.; Tabernero, J.; Janku, F.; Burris, H.A.; Schellens, J.H.M.; Middleton, M.R.; Berlin, J.; Schuler, M.; Gil-Martin, M.; et al. JOURNAL OF CLINICAL ONCOLOGY Phosphatidylinositol 3-Kinase a-Selective Inhibition With Alpelisib (BYL719) in PIK3CA-Altered Solid Tumors: Results From the First-in-Human Study. J. Clin. Oncol. 2018, 36, 1291-1299. [CrossRef]

66. Ferrarotto, R.; Mitani, Y.; Diao, L.; Guijarro, I.; Wang, J.; Zweidler-McKay, P.; Bell, D.; William, W.N., Jr.; Glisson, B.S.; Wick, M.J.; et al. Activating NOTCH1 Mutations Define a Distinct Subgroup of Patients With Adenoid Cystic Carcinoma Who Have Poor Prognosis, Propensity to Bone and Liver Metastasis, and Potential Responsiveness to Notch1 Inhibitors. J. Clin. Oncol. 2017, 35, 352-360. [CrossRef]

67. Hapuarachi, B.S.; Feeney, L.; Rack, S.; Adderley, H.; Morgan, D.; Betts, G.; Walker, R.; Rauch, R.; Herz, E.; Harrington, K.J.; et al. Clinical Disease Course and Survival Outcomes Following Disease Recurrence in Adenoid Cystic Carcinoma (ACC) with NOTCH Signaling Pathway Activation. J. Clin. Oncol. 2021, 39, 6072. [CrossRef]

68. Kang, J.H.; Lee, S.H.; Lee, J.; Choi, M.; Cho, J.; Kim, S.J.; Kim, W.S.; Ko, Y.H.; Yoo, H.Y. The Mutation of BCOR Is Highly Recurrent and Oncogenic in Mature T-Cell Lymphoma. BMC Cancer 2021, 21, 82. [CrossRef]

69. Rothwell, D.G.; Ayub, M.; Cook, N.; Thistlethwaite, F.; Carter, L.; Dean, E.; Smith, N.; Villa, S.; Dransfield, J.; Clipson, A.; et al. Utility of CtDNA to Support Patient Selection for Early Phase Clinical Trials: The TARGET Study. Nat. Med. 2019, 25, 738-743. [CrossRef]

70. Sun, J.; Liu, S.; Fu, K.; Gao, N.; Li, R.; He, W.; Gao, Z. Clinicopathological Characteristics and Outcomes of 23 Patients with Secretory Carcinoma of Major Salivary Glands. Sci. Rep. 2021, 11, 22639. [CrossRef] 